\title{
GASTRONOMIA E NUTRIÇÃO: PERSPECTIVA PESSOAL E PROFISSIONAL
}

\author{
GASTRONOMÍA Y NUTRICIÓN: PERSPECTIVA PERSONAL Y PROFESIONAL \\ GASTRONOMY AND NUTRITION: PROFESSIONAL AND PERSONAL \\ POINT OF VIEW
}

Andréa Carla Mendonça de Souza PAIVA ${ }^{1}$

RESUMO: A gastronomia é uma ciência estudada há muitos séculos por vários pesquisadores, os quais buscam conhecer esse campo para além dos princípios culinários. É importante destacar que vários equipamentos, utensílios e processos culinários surgiram da curiosidade desses estudiosos. No entanto, esse campo ainda é relativamente desconhecido no meio científico que se dedica a pesquisar a área de nutrição. Embora já tenha sido incluído na grade curricular dos cursos de Nutrição, a perspectiva apresentada sobre a gastronomia ainda é vista pelo prisma da culinária. Desse modo, esse ramo do conhecimento, que tem relação direta com a área de alimentação coletiva, poderia ser melhor explorado nas universidades em termos de pesquisa. Isso favoreceria diretamente o aprendizado dos recém-formados sobre a gastronomia, de forma mais ampla, e a gastronomia molecular, uma vez que o mercado de alimentação coletiva apresenta um crescimento e possui números expressivos de empregabilidade. Logo, diante desse contexto, apresento neste artigo um relato da minha experiência como nutricionista, ressalto as possibilidades que surgiram com o meu aprendizado sobre gastronomia e, além disso, apresento as dificuldades encontradas como docente para realizar visitas técnicas de fins pedagógicos às indústrias da área de alimentação.

PALAVRAS-CHAVE: Nutricionista. Gastronomia molecular. Formação complementar. Professor.

RESUMEN: La gastronomía es una ciencia estudiada hace muchos siglos por varios investigadores, los cuales buscan conocer ese campo más allá de los principios culinarios. Es importante tener en cuenta que varios equipos, utensilios y procesos culinarios surgieron de la curiosidad de esos estudiosos. Sin embargo, este campo todavía es relativamente desconocido en el medio científico que se dedica a investigar el área de nutrición. Aunque ya se ha incluido en la rejilla curricular de los cursos de Nutrición, la perspectiva presentada sobre la gastronomía permanece bajo la mirada de la culinaria. Por lo tanto, esa rama del conocimiento, que tiene relación directa con el área de alimentación colectiva, podría ser mejor explotada en las universidades para investigación académica. Esto favorecería el aprendizaje de los recién formados sobre la gastronomía, de manera más amplia, y la gastronomía molecular; una vez que el área de

1 Universidade Federal Rural de Pernambuco (UFRPE), Recife - PE - Brasil. Professora Doutora do Departamento de Morfologia e Fisiologia Animal, área de Bioquímica e Biofísica. ORCID: <http://orcid.org/0000-0003-4650-1823>. E-mail:andreacarlams@ gmail.com.

RIAEE - Revista Ibero-Americana de Estudos em Educação, Araraquara, v. 13, n. 2, p. 748-763, abr./jun., 2018. E-ISSN: $1982-5587$. 
alimentación colectiva está en crecimiento y presenta gran empleabilidad. A este respecto, presento en este artículo un relato de mi experiencia profesional como nutricionista. También destaco las posibilidades que surgieron durante mi aprendizaje en el área de gastronomía y, además, presento las dificultades encontradas como docente para realizar visitas técnicas de fines pedagógicos a las industrias de alimentación.

PALABRAS-CLAVE: Nutricionista. Gastronomía molecular. Profesor. Formación complementaria.

ABSTRACT: Gastronomy is a science studied many centuries ago by several researchers who seek to know this field beyond the cooking principles. It is important to highlight that several equipment, utensils and culinary processes arose from the curiosity of these scholars. However, this field is still relatively unknown in the scientific environment that is dedicated to research the nutrition. Although it has already been included in the curriculum of Nutrition courses, the perspective of the gastronomy is still under the point ofview of cooking. Therefore, this field of knowledge, which is directly related to the collective dietstudy, could be better explored in universities, more specifically in the academic research. This would favor the learning process of recentgraduates, both in gastronomy and molecular gastronomy, since the collective diet labor market is growing and has a high rate of employability. Based on these considerations, I present in this paperan experience report as a nutritionist. I also highlight here the possibilities that have arisen during my learning about gastronomy; and, in addition to that, I note the difficulties encountered as a professor to carry out technical visits for pedagogical purposes to the food industry.

KEYWORDS: Nutritionist. Dietitian. Molecular gastronomy. Education. Professor.

\section{Introdução}

A Nutrição busca pesquisar, conhecer e interpretar todos os fenômenos relacionados aos alimentos e às substâncias nutritivas. Ela estuda todos os mecanismos por meio dos quais seres vivos recebem e utilizam os nutrientes necessários a seu bom funcionamento orgânico (DUTRA DE OLIVEIRA; MARCHINI, 1998). Outra definição para esse ramo do conhecimento seria a seguinte: "a ciência que estuda a composição dos alimentos e as necessidades nutricionais do indivíduo, em diferentes estados de saúde e doenças." (DEFINIÇÕES, 2012, s/p). Desse modo, a nutrição constitui um conjunto de fenômenos físicos, químicos, físico-químicos e fisiológicos que se passam no interior do organismo e mediante os quais este recebe e utiliza os materiais fornecidos pelos alimentos - isto é, os nutrientes, os quais são necessários para a formação e manutenção de toda matéria viva - no nosso organismo. Em relação à "dietética", segundo Todhunter (1965 
apud TOLOZA, 2003), a palavra "dieta" refere-se à aplicação prática da nutrição a indivíduos, grupos sadios ou enfermos ${ }^{2}$.

No que diz respeito ao surgimento da profissão de Nutricionista, há várias teorias. No entanto, o primeiro curso universitário de dietista relatado data de 1902, na Universidade de Toronto, no Canadá; embora, é importante ressaltar, a importância da alimentação no tratamento de doenças tenha aparecido bem antes, em 1670. Os registros apresentam ainda a atuação das Irmãs da Ordem de Ursulinas em Quebec, no mesmo país.

De acordo com Guedes, Calado e Pacheco (2014), o primeiro curso de Nutrição no Brasil surgiu em 1939, na Universidade de São Paulo (USP), a saber, no Instituto de Higiene de São Paulo, por iniciativa do médico Geraldo de Paula Souza. Em 30 de abril de 1943, na Universidade Federal do Estado do Rio de Janeiro (UNIRIO), foi criado o curso de nutricionista do Serviço de Alimentação da Previdência Social (SAPS); e, em 24 de maio de 1944, na Universidade do Estado do Rio de Janeiro (UERJ), o curso de nutricionista da Escola Técnica de Assistência Social Cecy Dodsworth. Em 10 de janeiro de 1946, foi criado o Instituto de Nutrição da Universidade do Brasil, na Universidade Federal do Estado do Rio de Janeiro, por iniciativa de Josué de Castro, médico que realizou o primeiro Inquérito Nutricional nacional no Brasil, além de conhecido autor de vários livros, como o Geografia da Fome e Geopolítica da Fome. Já na década de 50, são criados os cursos de Nutrição na região Nordeste: primeiro na Bahia, na Universidade Federal da Bahia (UFBA), em 12 de abril de 1956; e, depois, em Pernambuco, na Universidade Federal de Pernambuco (UFPE), em 26 de abril de 1957. Ambos foram criados pelo professor Nelson Chaves, o qual também colaborou com a criação do curso no Rio Grande do Norte, mais precisamente na Universidade Federal do Rio Grande do Norte (UFRN)

Segundo Guedes, Calado e Pacheco (2014), até 1968 eram seis cursos de Nutrição no país. Calado (2000) relatou a existência de 106 cursos no Brasil, sendo 22 públicos e 84 privados. Em janeiro de 2018, a autora supracitada apontou que, na atualidade, existem 1.461 cursos. Portanto, conforme se constata, a profissão teve um crescimento expressivo nos últimos 20 anos. Interessante apontar que, há sessenta anos, quando surgira a profissão de nutricionista, conforme afirma Vasconcelos (2002), o desafio do profissional era a superação de um perfil epidemiológico nutricional característico daquela época, cujo

\footnotetext{
2 Já nos escritos atribuídos a Hipócrates, se encontrava a expressão “dietética”.
} 
destaque eram as doenças carenciais - tais como desnutrição protéico-calórica, hipovitaminose A, pelagra, anemia ferropriva, entre outras - as quais estavam:

[...] associadas às condições de "subdesenvolvimento", de pobreza, de fome, de desigualdades regionais. Nos dias atuais, àquele perfil epidemiológico sobrepuseram-se as doenças nutricionais degenerativas (obesidade, diabetes, dislipidemias etc.), associadas às condições de "desenvolvimento" e de "modernidade" existentes no país e, assim, novos dilemas e desafios são apresentados aos nutricionistas (VASCONCELOS, 2002, p. 36).

Sendo assim, em razão das condições dos anos 60 e 70, a ênfase maior na Nutrição foi dada às Ciências da Saúde. Desde aquela época, as áreas mais procuradas pelos profissionais de Nutrição para trabalhar continuam a ser de nutrição clínica, saúde coletiva e alimentação coletiva - esta última, aliás, é a temática do presente artigo. Passamos, agora, a discutir a partir do relato da minha experiência como nutricionista recém-formada, as dificuldades que tive de superar para aprender sobre a temática Alimentação Coletiva no mercado gastronômico.

\section{Nutrição: áreas de atuação}

A Resolução n ${ }^{\circ}$ 380, de 25 de dezembro de 2005, do Conselho Federal de Nutrição (CFN) (BRASIL, 2005) apresenta detalhadamente as diferentes linhas de atuação em que o profissional de nutrição pode trabalhar, tais como: alimentação coletiva, nutrição clínica, saúde coletiva, docência, indústria de alimentos, nutrição em esportes, marketing na área de alimentação e nutrição. No Anexo II da Resolução supracitada, estão detalhadas as atribuições do Nutricionista na área de alimentação coletiva. Para este artigo, foi feito um recorte nos itens 1.1.1 e 1.1.2 do ponto 1.1. do documento, conforme pode ser lido a seguir:

1. UNIDADE DE ALIMENTAÇÃO E NUTRIÇÃO (UAN) - Compete ao Nutricionista, no exercício de suas atribuições em Unidades de Alimentação e Nutrição, planejar, organizar, dirigir, supervisionar e avaliar os serviços de alimentação e nutrição. Realizar assistência e educação nutricional a coletividade ou indivíduos sadios ou enfermos em instituições públicas e privadas.

1.1. Para realizar as atribuições definidas no item 1 , o nutricionista deverá desenvolver as seguintes atividades obrigatórias: 
1.1.1. Planejar e supervisionar a execução da adequação de instalações físicas, equipamentos e utensílios, de acordo com as inovações tecnológicas;

1.1.2. Planejar e supervisionar o dimensionamento, a seleção, a compra e a manutenção de equipamentos e utensílios;

1.1.3. Planejar, elaborar e avaliar os cardápios, adequando-os ao perfil epidemiológico da clientela atendida, respeitando os hábitos alimentares;

1.1.4. Planejar cardápios de acordo com as necessidades de sua clientela;

1.1.5. Planejar, coordenar e supervisionar as atividades de seleção de fornecedores, procedência dos alimentos, bem como sua compra, recebimento e armazenamento de alimentos;

1.1.6. Coordenar e executar os cálculos de valor nutritivo, rendimento e custo das refeições/preparações culinárias;

1.1.7. Planejar, implantar, coordenar e supervisionar as atividades de prépreparo, preparo, distribuição e transporte de refeições e/ou preparações culinárias;

1.1.8. Identificar clientes/pacientes portadores de patologias e deficiências associadas à nutrição, para o atendimento nutricional adequado;

1.1.9. Coordenar o desenvolvimento de receituários e respectivas fichas técnicas, avaliando periodicamente as preparações culinárias;

1.1.10. Estabelecer e implantar procedimentos operacionais padronizados e métodos de controle de qualidade de alimentos, em conformidade com a legislação vigente;

1.1.11. Coordenar e supervisionar métodos de controle das qualidades organolépticas das refeições e/ou preparações, por meio de testes de análise sensorial de alimentos;

1.1.12. Elaborar e implantar o Manual de Boas Práticas, avaliando e atualizando os procedimentos operacionais padronizados (POP) sempre que necessário;

1.1.13. Planejar, implantar, coordenar e supervisionar as atividades de higienização de ambientes, veículos de transporte de alimentos, equipamentos e utensílios;

1.1.14. Planejar, coordenar, supervisionar e/ou executar programas de treinamento, atualização e aperfeiçoamento de colaboradores;

1.1.15. Promover programas de educação alimentar e nutricional para clientes;

1.1.16. Participar da elaboração dos critérios técnicos que subsidiam a celebração de contratos na área de prestação de serviços de fornecimento de refeições para coletividade;

1.1.17. Acompanhar os resultados dos exames periódicos dos clientes/pacientes, para subsidiar o planejamento alimentar;

1.1.18. Detectar e encaminhar ao hierárquico superior e às autoridades competentes, relatórios sobre condições da UAN impeditivas da boa prática profissional e/ou que coloquem em risco a saúde humana;

1.1.19. Elaborar o plano de trabalho anual, contemplando os procedimentos adotados para o desenvolvimento das atribuições;

1.1.20. Efetuar controle periódico dos trabalhos executados;

1.1.21. Colaborar com as autoridades de fiscalização profissional e/ou sanitária;

1.2. Ficam definidas como atividades complementares do nutricionista na UAN:

1.2.1. Participar do planejamento e gestão dos recursos econômicofinanceiros da UAN; 
1.2.2. Participar do planejamento, implantação e execução de projetos de estrutura física da UAN;

1.2.3. Implantar e supervisionar o controle periódico das sobras, do restoingestão e análise de desperdícios, promovendo a consciência social, ecológica e ambiental;

1.2.4. Participar da definição do perfil, do recrutamento, da seleção e avaliação de desempenho de colaboradores;

1.2.5. Planejar, supervisionar e/ou executar as atividades referentes a informações nutricionais e técnicas de atendimento direto aos clientes/pacientes;

1.2.6. Planejar e/ou executar eventos, visando à conscientização dos empresários da área e representantes de instituições, quanto à responsabilidade dos mesmos na saúde coletiva e divulgando o papel do Nutricionista;

1.2.7. Organizar a visitação de clientes às áreas da UAN;

1.2.8. Realizar e divulgar estudos e pesquisas relacionados à sua área de atuação, promovendo o intercâmbio técnico científico;

1.2.9. Prestar serviços de auditoria, consultoria e assessoria na área;

1.2.10. Participar do planejamento e execução de programas de treinamento, estágios para alunos de nutrição e educação continuada para profissionais de saúde, desde que sejam preservadas as atribuições privativas do nutricionista (BRASIL, 2005, s/p).

\section{A Gastronomia para além da arte culinária}

Nóbrega (2018) ressalta a complementaridade da Gastronomia e da Nutrição e a pouca ênfase dada à primeira na formação do Nutricionista. $\mathrm{O}$ autor também aponta que, mesmo quando a gastronomia é estudada, contextualiza-se apenas o aspecto relacionado à arte culinária. No entanto, em 1783, o químico francês Antoine-Laurent de Lavoisier já dava início aos estudos científicos sobre as preparações culinárias para avaliar a qualidade do preparo de caldos, o que era feito medindo a densidade do produto final. Ademais, em 1794, o físico norte-americano Benjamin Thompson percebera o quanto a arte culinária poderia ser melhorada com a aplicação de descobertas científicas e químicas - ele foi nada menos que o inventor da máquina de fazer café. Após quase 60 anos, o químico alemão Justus von Liebig observara que os sucos da carne tinham alto valor nutricional, e que a única maneira de preservá-los era selando a peça em altas temperaturas (DÓRIA, 2009; MCGEE, 1992; THIS, 2008).

No entanto, o advogado, político e cozinheiro francês Jean Anthelme BrillatSavarin (1755-1826) já apresentava o campo da Gastronomia como ciência em potencial esse mesmo autor desenvolveu um conhecimento racional, uma reflexão filosófica sobre a nutrição humana. Na sua obra Fisiologia do Gosto, publicada em 1825, Brillat-Savarin descreve a gastronomia como o conhecimento fundamentado de tudo o que se refere ao 
homem, na medida em que ele se alimenta. A gastronomia, na perspectiva desse autor, tinha por objetivo zelar pela conservação dos homens por meio da melhor alimentação possível, meta que seria atingida por meio da orientação, mediante princípios seguros, de todos os que pesquisam, fornecem ou preparam os produtos que podem se converter em alimentos. Nesse livro, o cozinheiro francês ressalta também a multidisciplinaridadedo campo gastronômico. Assim, gastronomia e nutrição são multidisciplinares, pois ambas estão relacionadas à história natural, ao classificar as substâncias alimentares; à física, ao examinar os componentes e suas qualidades; à química, ao analisar as substâncias e os efeitos da decomposição; à culinária, ao preparar uma receita e deixá-la agradável ao gosto, ao aroma, à visão, além de nutritiva; ao comércio, ao observar os custos; à economia política, ao ter relação com as fontes de renda que se apresentam à tributação e por meios de troca, que se estabelecem entre as nações.

Então, a gastronomia não se estagnou, mas, ao contrário, foi se modificando com o tempo, principalmente a partir do século XX, quando começou um intercâmbio cultural e gastronômico que possibilitou a difusão de ingredientes pelo mundo (FRANCO, 2006). De acordo com Sacaldassy (2018), tal movimento, ao longo dos anos, fez surgir a curiosidade de dois cientistas - a saber, Nicholas Kurti e Hervé This - que começaram a explorar a ciência da cozinha tentando melhorar os processos de elaboração de pratos culinários. Nicholas Kurti, físico húngaro, participou do Projeto Manhatan, o qual desenvolveu a bomba atômica norte-americana. Segundo O'Connell (2006), nos anos 60, em Oxford, no Reino Unido, Kurti já refletia sobre o fato dos pesquisadores saberem mais sobre a temperatura das estrelas do que da temperatura de um suflê; isso apontava para a sua frustração em relação à falta de tratamento científico dado às artes culinárias. O'Connell (2006) relata ainda que, em 1980, Hervé This, físico e químico francês que trabalhava no Instituto Nacional de La Recherche Agronomique (INRA), em Paris, na França, também refletia sobre o que acontecia nas preparações culinárias. Relata-se que um dia, quando Hervé This fora receber amigos em sua casa, na hora de preparar um suflê de roquefort, ele havia lido na receita que teria de colocar as gemas duas a duas; porém, ao considerar a indicação sem importância, decidiu colocar todas de uma vez e o resultado foi um prato horrível.

Os dois cientistas, isoladamente, começaram a fazer pesquisas sobre as informações empíricas das receitas que liam ou ouviam, e sobre os mitos culinários transmitidos pelas donas de casa idosas (RODRIGO, 2018). Em um desses mitos, que This e Kurti puseram à 
prova, estavam as dicas para o preparo da maionese: (1) as mulheres menstruadas não deveriam preparar a maionese, pois a temperatura das mãos mudava e o prato poderia "desandar"; e (2) o sentido dos movimentos enquanto se mistura os ovos e o óleo não pode mudar. A primeira dica, claro, é um mito. Todavia a maionese realmente só deve ser mexida em um sentido, pois a mistura pode "desandar". A explicação científica é a seguinte: a maionese é uma emulsão e, portanto, são coloides do tipo líquido-líquido, isto é, gotinhas líquidas minúsculas suspensas em outro líquido mais denso. $\mathrm{O}$ creme "desanda" porque, ao inverter o sentido da mistura, fecha-se o pouco espaço em que as gotículas de óleo deveriam ficar suspensas e elas, ao ocupar espaços vazios na mistura, acabam por se chocar. A emulsão, consequentemente, se desfaz, ou então, se você preferir a explicação simplificada, “desanda.” (RODRIGO, 2018, s/p).

Em 1986, Nicholas Kurti e Hervé This se conheceram e deram início a uma frutífera troca de conhecimentos sobre os experimentos que ambos faziam, resultando no primeiro workshop sobre o tema - intitulado Gastronomia Física e Molecular - que aconteceu em 1992 na Itália. O evento foi a pedra fundamental para a consolidação do surgimento da Gastronomia Molecular. Interessante destacar que This (2006 apud RODRIGO, 2018) enfatiza a existência de uma confusão entre Gastronomia Molecular (GM) e o que ele denomina de Cozinha Molecular - esta última diz respeito à área em que "se procuram novas ferramentas, ingredientes e métodos de se preparar os alimentos" (RODRIGO, 2018, s/p).

Segundo This (2006), a Gastronomia Molecular apresenta cinco objetivos:

- Criação de uma Antropologia Culinária, isto é, recenseamento e exploração físicoquímica das "dicas” culinárias;

- Introdução de Matemáticas Culinárias, ou seja, modelização de práticas culinárias visando ao aperfeiçoamento;

- Experimentação, isto é, introdução de instrumentos, métodos e ingredientes novos na cozinha doméstica ou de restaurante;

- Inovação ou criação de novos pratos, com base na análise de iguarias clássicas;

- Divulgação, ou seja, apresentação da ciência ao público, considerando as práticas culinárias.

This (2006 apud RODRIGO, 2018) enfatiza que a Gastronomia Molecular não é uma tecnologia, mas uma ciência, embora "tecnologistas" ou engenheiros possam usar o conhecimento para produzir inovação na cozinha. Os experimentos em Gastronomia 
Molecular são profundos, complexos, longos e requerem rigor e métodos científicos; os resultados dos experimentos não são inovadores, mas podem ser aplicados para produzir inovações nos processos.

Ademais, ao enfatizar a importância da gastronomia para além das preparações culinárias, é interessante ressaltar que a Gastronomia Molecular é uma subdisciplina da Ciência dos Alimentos. A cozinha é um laboratório; quando há o entendimento do modo de produzir os alimentos e seus processos, existe a possibilidade de descobrir e colaborar com o futuro da alimentação. E é fazendo uso da pesquisa em Gastronomia Molecular que poderá ser possível explicar as transformações físicas e químicas dos ingredientes durante o cozimento, assim como todos os componentes sociais, artísticos e técnicos dos fenômenos culinários e gastronômicos em geral.

\section{O Nutricionista: sua atuação na área de Alimentação Coletiva}

As Diretrizes Curriculares Nacionais do Curso de Graduação em Nutrição, descritas na Resolução CNE/CES ${ }^{3}$ n $^{\circ} 5$, de 7 de novembro de 2001, ressaltam o perfil generalista do profissional formado. $\mathrm{O}$ artigo 5 , inciso XII, apresenta as habilidades e competências em relação a "desenvolver atividades de auditoria, assessoria, consultoria na área de alimentação e nutrição". Volto a reportar a Resolução n 380 de 25 de dezembro de 2005 do CFN (BRASIL, 2005), subitens 1.1.1 e 1.1.2, em que teoricamente foi estabelecido que o profissional nutricionista também deve estar apto a planejar e supervisionar a execução da conformidade de instalações físicas, equipamentos e utensílios, de acordo com as inovações tecnológicas; além disso, poderá planejar e supervisionar o dimensionamento, a seleção, a compra e a manutenção de equipamentos e utensílios.

A abordagem agora será direcionada ao setor de alimentação, segmento cuja representatividade no $\mathrm{PIB}^{4}$ brasileiro chega atualmente a 2,7\%, de acordo com os dados de 2017 da Associação Brasileira de Bares e Restaurantes (ABRASEL). Conforme informações do Instituto Brasileiro de Geografia e Estatística (IBGE) desse mesmo ano (BRASIL, 2017), o hábito da alimentação fora de casa cresce cada vez mais e corresponde a $31,1 \%$ dos gastos dos brasileiros com alimentos. Ainda segundo a ABRASEL (PECLY, 2017), a área de alimentação coletiva, também denominada de alimentação fora de casa ou de bares e restaurantes - apresenta expansão anual em torno de $10 \%$, gerando cerca de

${ }^{3}$ Conselho Nacional de Educação/Câmara de Educação Superior respectivamente.

${ }^{4}$ Produto Interno Bruto.

RIAEE - Revista Ibero-Americana de Estudos em Educação, Araraquara, v. 13, n. 2, p. 748-763, abr./jun., 2018. E-ISSN: $1982-5587$. 
450 mil novas oportunidades de emprego por ano. Assim, embora o setor tenha sido fortemente afetado pela crise político-econômica do país, as vendas cresceram o dobro em 2017, cuja estimativa de 2,5\% passou para 4,5\%. Para o ano de 2018, a previsão é de que este número germine, sendo esperados 300 mil novos postos de trabalho.

E nesse contexto de clara expansão do mercado de alimentação coletiva, surgem mudanças na área de atuação do profissional de nutrição. Segundo Ansaloni (1999), surge o nutricionista-administrador, o qual agora tem um novo desafio profissional com escopo e complexidade do trabalho ampliados. Esse novo papel traz à tona a premência de estabelecimento de interfaces da Nutrição com outras áreas do conhecimento, tais como a gastronomia.

\section{Gastronomia e Nutrição: perspectiva pessoal e profissional}

A partir desse momento, faço uma explanação sobre a minha trajetória profissional, a qual se dá muito antes do período em que me formei, a saber, em 2002.

Ingressei no curso de Nutrição na Universidade Federal do Rio Grande do Norte (UFRN) no segundo semestre de 1997. Desde a época de graduação que atuo na área de Alimentação Coletiva. Minha trajetória tem início como estagiária voluntária do Restaurante Universitário; posteriormente, fui estagiária remunerada de uma empresa de catering aéreo (serviço de refeições a bordo, que prestava serviços à Varig, VASP e Trip). Já recém-formada, decidi fazer o mestrado em Recife, no Departamento de Nutrição da Universidade Federal de Pernambuco (UFPE), no qual escolhi a área de Ciências dos Alimentos. Na ocasião, para me manter financeiramente, pois não tinha bolsa de estudos, comecei a atuar como personal diet - isso em meados de 2003, quando poucas pessoas faziam esse tipo de serviço, e o meu atendimento era na casa do cliente. Ao mesmo tempo, passei a atuar na área de controle de qualidade de alimentos em restaurantes gastronômicos. Essas duas linhas de trabalho foram o início da minha vida profissional na gastronomia.

Quando fui atuar como personal diet, comecei atendendo alguns empresários com alto poder aquisitivo, cujas cozinhas eram equipadas com o que havia de mais moderno em termos de tecnologia de utensílios e equipamentos, muitas vezes importados. Os planos alimentares criados por mim tinham que incluir jantares acompanhados com vinhos, pelo menos duas vezes por semana. Como personal diet, meu serviço incluía plano alimentar, 
visita à cozinha, adequação das compras para diminuir desperdícios, treinamento dos empregados em relação a boas práticas de manipulação e preparações culinárias, compra de alimentos e seu armazenamento. Tais atividades me levavam a entrar nas casas dos clientes: foi assim que comecei a ver os equipamentos que alguns deles tinham em casa, muitos dos quais eu nunca tinha visto. Desse modo, por necessidade de aprender para ensinar, comecei a estudar sobre geladeiras, freezers e centrífugas especiais para sucos. Também comecei a estudar sobre congelamento, vinhos e uma infinidade de alimentos que eu nunca tinha ouvido falar - tais como aspargos, cogumelos dos mais variados tipos, queijos franceses etc. -, ou seja, estava diante de um longo aprendizado para entender quais eram os ingredientes que meus clientes consumiam e como prepará-los. Eu ainda visitava os lugares em que eles comiam e, desse modo, conseguia adequar a realidade alimentar de cada um em um específico plano nutricional para que tivessem maior adesão.

Ao mesmo tempo, continuava a operar no controle de qualidade de restaurantes gastronômicos, estabelecimentos cujos cardápios são mais elaborados e normalmente estão associados a um grande "chef" ou cozinheiro de nome. Tive que estudar a tipologia de restaurantes, os equipamentos que existiam nesses locais, o processo de Cook Chill (congelamento e resfriamento rápido), o de cozimento a vácuo (sous vide) e o uso de robôs de cozinha. Precisei aprender sobre a manutenção, as características dos equipamentos e a limpeza eficiente para poder ensinar aos manipuladores. Estudei os diferentes utensílios disponíveis nos estabelecimentos, como os decanter, utilizados para o vinho respirar e assim, liberar seus melhores aromas e sabores. Ora, como higienizar corretamente sem quebrar um acessório com formato (variável) tão complexo? Também fui "obrigada" a estudar o dimensionamento e o design de restaurantes. Destaco que, até então, tinha estudado na universidade apenas dimensões institucionais, ou seja, enormes. E na área de restauração, na maioria dos casos, as dimensões são bem menores, mas você precisa construir o fluxograma de adequação para diminuir os riscos de contaminação cruzada. Imaginem que isso tudo aconteceu por volta de 2003 até meados de 2005, início da explosão da gastronomia no Brasil e no estado de Pernambuco. Desse modo, não havia tanta disponibilidade de informação sobre o assunto, e eu não havia visto muita coisa sobre a temática na universidade, onde o aprendizado se limitou à alimentação coletiva do tipo institucional.

Em 2007, fiz concurso para professora substituta do curso de Bacharelado em Gastronomia da Universidade Federal Rural de Pernambuco (UFRPE), primeiro curso 
público de gastronomia do país, nas disciplinas de Planejamento e Organização de Eventos, Serviços de Bares e Restaurantes e Gastrotenia (disciplina similar à técnica dietética). Outro aprendizado, afinal, na minha formação de nutricionista não havia nada sobre tecnologia de bebidas e, por isso, fui novamente "do zero" estudar o processamento delas. Quanto à disciplina de eventos, a experiência foi muito interessante, uma vez que o nutricionista, quando inserido em uma unidade de alimentação, sempre é o responsável pelos eventos, tendo em vista que todos têm comida; todavia, não existe nada sobre a temática durante o processo de formação do nutricionista. Recordo-me que, ao fazer estágio na Maternidade Escola Januário Cicco da UFRN (MEJC-UFRN), uma das minhas primeiras tarefas foi organizar um café da manhã para o governador do estado do Rio Grande do Norte, na ocasião, Garibaldi Alves. Nesse momento, lembro que uma das nutricionistas me olhou e solicitou que orientasse o cardápio do café da manhã para a vinda do governador, ou seja, o setor de nutrição normalmente se responsabiliza pelos eventos dos locais.

Em 2008, no início, prestei concurso para professora efetiva das disciplinas de Habilidades e Técnicas Culinárias e Cozinha Clássica (Cozinha francesa). Novamente tive que estudar, mas não com tanta dificuldade, tendo em vista que já estava ambientada na área. Como eu não era totalmente distante da cozinha, pesquisei, separei preparações típicas e fui praticar, uma vez que cozinha é realmente prática. No ano de 2015, novamente uma mudança em minha vida: fui remanejada para a área de bioquímica, em outro departamento da UFRPE. É lá que estou atualmente como responsável pelas disciplinas de Bioquímica de Alimentos, a qual é ofertada ao curso de Gastronomia, e Bioquímica para o curso de Zootecnia; e, em alguns momentos, leciono Bioquímica da Nutrição para o curso de Economia Doméstica.

No entanto, qual o motivo de escrever tudo isso? A quem interessa a minha trajetória? Após tantos anos atuando na gastronomia, conversando informalmente com vários chefs de cozinha do país inteiro, observo que todos têm o mesmo posicionamento sobre os nutricionistas que chegam para atuar nos restaurantes - "não conhecem os equipamentos, utensílios, acessórios" e "não percebem a gastronomia como ciência e sim como o ato de cozinhar". E quando eles descrevem os profissionais da atualidade, lembro de mim quando comecei, pois como nutricionista recém-formada, eu desconhecia os equipamentos, não sabia as especificações técnicas dos mesmos, quais os tipos de aço 
usados nas cozinhas, os tipos de piso adequados (classificação $\mathrm{PEI}^{5}$ ), as calhetas sifonadas em inox usadas para escoamento de água, os acessórios específicos para a gastronomia, como taças diversas e moedores de pimenta, etc. Enfim, uma nutricionista que, embora conhecesse as Portarias e Resoluções que norteavam o controle de qualidade, desconhecia os materiais e o ambiente no contexto geral em que atuava, a saber, os restaurantes gastronômicos. Em outras palavras, eu não tinha noção do que era gastronomia e, tampouco, a gastronomia molecular. Também não tinha ideia que a temática poderia ser um campo de pesquisa, já que é uma ciência e deve ser explorada como tal. Para mim, aprender sobre o assunto foi uma grande construção, de um mundo novo, dinâmico, em constante transmutação. Ademais, em todos os semestres aparecem novos tópicos; passados quase 10 anos na área, eu continuo compondo, dia a dia, tijolo por tijolo, o meu aprendizado em gastronomia.

Atualmente, como professora, responsável por transformar a informação em formação, minha preocupação é como contextualizar a teoria na realidade. Não atuo na formação de nutricionistas, atuo na formação de gastrônomos e zootecnistas, porém minha preocupação é a mesma com meus alunos desses cursos. Tento apresentar a disciplina de Bioquímica dos Alimentos e a Bioquímica contextualizando a realidade do mercado.

No entanto, escrevendo uma parte da minha história profissional, minha construção como nutricionista que atua na área de gastronomia, me dou conta de como foi fazer esta aproximação entre teoria e prática. $\mathrm{Na}$ ocasião, como consultora, era mais fácil, pois estava inserida no mercado. Atualmente, como docente, tento fazer essa aproximação por meio de estudo, de pesquisa sobre a temática e a teoria, mas no que diz respeito à prática, o que acontece realmente no mercado, sinto dificuldade em apresentar. As empresas não facilitam o acesso às suas instalações - refiro-me aqui a fábricas de equipamentos, utensílios, acessórios, alimentos, etc. É impressionante, mas eu, como professora, luto dia a dia para buscar abertura a visitas técnicas para corroborar com meu aprendizado e simplesmente não consigo. É uma batalha semestral que travo: são ligações, custeadas muitas vezes com recursos próprios, e numerosos e-mails. $\mathrm{Eu}$, como docente, recebo um convite de empresas para conhecer fábricas de alimentos, de processamento? Não, isso não acontece comigo. Recebo convites para feiras de equipamentos e utensílios ou para conhecer as fábricas de utensílios? Não, não recebo. Embora seja importante para o

${ }^{5}$ A escala PEI (Porcelain Enamel Institute) foi criada para classificar as cerâmicas. Sua variação de 0 a 5 nos informa que quanto mais elevado o número maior é a resistência ao desgaste superficial do esmalte da placa cerâmica,o qual pode se dar em decorrência do trânsito de pessoas e do contato com objetos. 
professor conhecer o que se faz de novo, o que há no mercado, o conteúdo não é percebido como relevante. E, para tornar a situação ainda mais delicada, as universidades não custeiam visitas de professores a feiras, a exposições de equipamentos. Antes custeava-se apenas idas a eventos científicos, quando o docente submetia trabalhos científicos; atualmente, nem isso, pelo menos na minha instituição, no tocante às questões de crise no custeamento da universidade.

No momento presente, no setor de restauração, busco fazer visitas a restaurantes para conhecer as instalações. Lá converso com os profissionais dos locais, os chefs, os nutricionistas e os administradores. Quando não tenho acesso, vou como cliente, uma vez que fica bem mais fácil para ter acesso, embora seja mais oneroso para mim. Pelo menos, consigo colocar na "lista" de estudos; e, dessa forma, vou adequando o conhecimento teórico com a prática vista nos locais que visito, nos diálogos que travo. Entendo que a minha vivência no mercado, seja como visitante, seja como cliente, me aproxima da prática do dia a dia, pois observo os processos e como isso pode colaborar com as disciplinas sob minha responsabilidade.

\section{Considerações finais}

Finalmente chego ao fim deste imenso texto. Não apresento soluções, o que costumeiramente é normal de acontecer com um artigo. No entanto, suscitarei algumas indagações: a) $\mathrm{O}$ que posso fazer para que os nutricionistas percebam a gastronomia para além dos princípios culinários?; b) De que modo posso apresentar as diversas tecnologias disponíveis no mercado na área de alimentação coletiva para que minha informação esteja adequada com a realidade, validando, assim, a formação do meu aluno?; c) O que é necessário para estimular a pesquisa nas áreas de gastronomia e gastronomia molecular?

Gostaria de afirmar que responder essas perguntas poderia fazer com que o recémformado estivesse capacitado de forma mais adequada para trabalhar na área de alimentação, que está em franca expansão, e que apresenta elevados índices de empregabilidade. Entretanto, não posso fazer tal declaração. Por outro lado, posso dizer que tais conhecimentos possibilitaram que o mercado me absorvesse facilmente quando ainda não era professora. E aqui não me refiro apenas à área de restauração, mas a de desenvolvimento de produtos, de utensílios, acessórios, etc. 
Para concluir, enfatizo a necessidade das empresas abrirem suas portas para o professor, o que seria importante para validar nossa aprendizagem, como um incremento para a formação discente. Ratifico que a interação professor $x$ indústria ainda não está realizada completamente. Nós, professores, somos influenciadores, mas as empresas ainda não entenderam isso. Lamentavelmente, a indústria ainda não percebeu o poder da nossa informação, da nossa voz.

\section{REFERÊNCIAS}

ANSALONI, J. A. Situação de trabalho dos nutricionistas em empresas de refeições coletivas de Minas Gerais: trabalho técnico, supervisão ou gerência? Revista de Nutrição, Campinas, v. 12, n. 3, p. 241-260, set./dez., 1999.

BRASIL. Instituto Brasileiro de Geografia e Estatística (IBGE). IBGE inicia a pesquisa de orçamentos familiares (POF) 2017/2018. Agência IBGE, Notícia, 26 jun. 2017, atual. 27 jun. 2017 às 10h37. Disponível em: <https://agenciadenoticias.ibge.gov.br/2013-agenciade-noticias/releases/10448-ibge-inicia-a-pesquisa-de-orcamentos-familiares-pof-20172018.html>. Acesso em: 17 fev. 2018.

BRASIL. Conselho Federal de Nutricionistas. Resolução n ${ }^{\circ}$ 380, de 28 de dezembro de 2005. Dispõe sobre a definição das áreas de atuação do nutricionista e de suas atribuições; também estabelece parâmetros numéricos de referência por área de atuação e dá outras providências. Diário oficial da União, 2005. Disponível em:

<http://www.cfn.org.br/wp-content/uploads/resolucoes/Res_380_2005.htm>. Acesso em: 24 jan. 2018.

BRASIL. Ministério da Educação. Conselho Nacional de Educação. Câmara de Educação Superior. Resolução n ${ }^{\circ}$, de 7 nov. 2001. Institui Diretrizes Curriculares Nacionais do Curso de Graduação em Nutrição. Diário Oficial da União, 2001. Disponível em: <http://portal.mec.gov.br/cne/arquivos/pdf/CES05.pdf>. Acesso em: 17 fev. 2018.

CALADO, C. L. A. A nova LDB e o curso de nutrição. Jornal do CFN, Brasília, v. 2, n. 6, p. 5, abr. 2000.

DEFINIÇÕES da Nutrição. Unidade de Gestão e Formação, 8 maio 2012. Disponível em: <http://www.posugf.com.br/noticias/todas/1580-definicoes-da-nutricao>. Acesso em: 19 fev. 2018.

DORIA, C. A. A culinária materialista: construção racional do alimento e do prazer gastronômico. São Paulo: Editora Senac São Paulo, 2009.

DUTRA DE OLIVEIRA, J. E.; MARCHINI, J. S. Ciências Nutricionais: aprendendo a aprender. 2. ed. São Paulo: Sarvier, 1998.

FRANCO, A. De caçador a gourmet: uma história da gastronomia. São Paulo: Editora Senac São Paulo, 2006. 
GUEDES, A. E. L.; CALADO, C. L. A.; PACHECO, N. M. D. (Orgs.). A nutrição no lado esquerdo do peito. 1 ed. Natal: Editora da UFRN - EDUFRN, 2014.

MCGEE, H. On food and cooking: the science and lore of the kitchen. Londres: Harper Collins Publishers, 1992.

NÓBREGA, A. B. N. Organização do programa da disciplina de introdução à gastronomiado curso de Nutrição da UFRN. Universidade Federal do Rio Grande do Norte (UFRN). Disponível em:

<http:arquivos.info.ufrn.br/arquivos/.../Comunidade_8.pdf>. Acesso em: 17 fev. 2018.

O'CONNELL, S. Kitchen Chemistry .BBC Focus, fev. 2006, p. 54-56. Disponível em: <http://sanjida.co.uk/pdf/kitchenchemistry.pdf>. Acesso em: 17 fev. 2018.

PECLY, J. Alimentação fora do lar indica recuperação. Folha de Pernambuco, Economia, Notícia, 3 out. 2017 às 7h10, atual. às 8h54. Disponível em:

<http://www.folhape.com.br/economia/economia/economia/2017/10/03/NWS,43797,10,55 0,ECONOMIA,2373-ALIMENTACAO-FORA-LAR-INDICA-RECUPERACAO.aspx>. Acesso em: 12 fev. 2018.

RODRIGO, E. A gastronomia molecular: a ciência na cozinha. Enio Rodrigo Portfolio, Reportagem, 8 nov. 2010. Disponível em: <https://eniorodrigo.wordpress.com/2010/11/08/gastronomia-molecular/>. Acesso em: 17 fev. 2018.

SACALDASSY, P. Gastronomia molecular. Santa Gastronomia. 2 jun. 2012. Disponível em: $\quad<$ https://santagastronomia.wordpress.com/category/principal/gastronomiamolecular/>. Acesso em: 17 fev. 2018.

THIS, H. Molecular gastronomy: Exploring the science of flavor. Columbia: Columbia University Press, 2008.

TOLOZA, D. C. Nutricionista: um histórico da profissão até os dias atuais. 2003. 57f. Trabalho de Conclusão de Curso (Especialização em Qualidade dos Alimentos) Universidade de Brasília, Centro de Excelência em Turismo, Brasília.

VASCONCELOS, F. A. G. O nutricionista no Brasil: uma análise histórica. Revista de Nutrição, Campinas, v. 15, n. 2, p. 127-138, maio/ago. 2002.

\section{Como citar este artigo:}

PAIVA, Andréa Carla Mendonça de Souza. Gastronomia e nutrição: perspectiva pessoal e profissional. Revista Ibero-Americana de Estudos em Educação, Araraquara, v. 13, n. 2, p. 748-763, abr./jun., 2018. E-ISSN: 1982-5587. DOI: 10.21723/riaee.v13.n2.2018.11111

Submissão em: 26/02/2018

Aprovação final em: 31/03/2018 